\title{
Assessment of Cancer Patient's Satisfaction Regarding Nurses \\ Communication Skills in Azadi Teaching Hospital/ Oncology unit
}

\author{
Dia'a AL-Rahman Abdullah*
}

Radhwan Hussien Ibrahim**

\begin{abstract}
Background and aim: Communication is the process of transmitting thoughts, feelings, facts, and other information, includes verbal and nonverbal behavior. Communication is an essential element of the nurseclient relationship, teaching of client, and entire activities performed by nurses. To be an effective communicator, the nurse must be aware of the different levels on which communication is conducted between nurses and clients and among members of the health care team. Applying the aspects of communication level helps the nurse establish a therapeutic relationship with the client and thereby achieve successful outcomes of care. The study aims to assess Cancer Patient's Satisfaction Regarding Nurses Communication Skills in Azadi Teaching Hospital as well as to find out the relationship between Patient's Satisfaction and some Socio- demographic characteristic such as age, gender and level of education.
\end{abstract}

Materials and method: A descriptive study of a quantitative design was carried out at oncology unit in Azadi teaching hospital in Kirkuk city for cancer patients from ${ }^{\text {st }}$ of December, 2015, up to the $16^{\text {th }}$ of February, 2016. A non-probability (convenience) sample of $(12 \cdot)$ definitely diagnosed with cancer disease. Selected from patients who were attended to Azadi teaching hospital generally for receiving chemotherapy dosage. Developed questionnaire was constructed for the purpose of the study which consisted of three parts: the demographic data of the respondent, the nature nurse-client relationship, and satisfaction regarding therapeutic communication. The data were collected through the use of interview with the patients. They were analyzed through the application of descriptive statistical analysis and inferential statistical data analysis.

Results: The findings of the study indicated that (24.2\%) of the samples were in age group (50-59) years and $(\geq 60)$ years, $(51.7 \%)$ of them were male, $(32.5 \%)$ of the sample were illiterate, $(40.0 \%)$ of them were housewife, $(87.5 \%)$ of the sample were married, $(79.2 \%)$ of the sample were urban residency, $(23.3 \%)$ of the sample had have breast cancer, and $(70.8 \%)$ of the sample were staying $\geq 1$ day in the hospital.

Conclusions: the study concluded that most of the patients were dissatisfied regarding the nature of Nurse-Patient communication. Most of patients were satisfied regarding Therapeutic communication.

\section{RECOMMENDATIONS}

The present study recommends that trained educational program should be designed to increase nurses' awareness and knowledge about modes of communication.

Keywords: cancer patients, communication skills, satisfaction.

\section{INTRODUCTION}

The positive results of effective communication are well documented and are essential in achieving, amongst others, increased recovery rates, a sense of safety and protection, improved levels of patient satisfaction and greater adherence to treatment options. Aside from these, successful communication through a patient-centered approach also serves to reassure relatives that their loved ones are receiving the necessary treatment. Within the nursing field, such skills are considered indicative of best practice (McCabe and Timmins, 2006). Today patient satisfaction counts as an important indicator in the assessment of the quality of healthcare services (Westbrook, 1993; Kurpas and Steciwko, 2005). Low patient satisfaction may result in loss of trust and consequently changing the treating physician or the healthcare center or even discontinuing treatment (Keating et. al., 2002). In addition, it may lead to suing the physicians, the healthcare system, and malpractice lawsuits (Stelfox et. al., 2005, Hickson et. al., 1994). Therefore, patient satisfaction and the mutual benefits to patients and healthcare systems particularly to physicians have been widely researched and emphasized recently. Patient satisfaction is influenced by several factors that include different aspects of healthcare services such as increased hospital facilities, increased number of personnel, and accessibility to primary healthcare services and reduced wait time for receiving healthcare services (Billing et. al., 2007, Pitrou et. al., 2009). As professionals, oncology nurses play

* Assistant Lecturer/ College of Nursing/ Kirkuk University

** Professor/College of Nursing/University of Mosul 
an important role in cancer diagnosis and management and they contribute toward their patients' quality of life and survival. For nurses to be effective in fulfilling their roles, they must have a well-defined set of professional competences to ensure that they are able to deliver the highest quality nursing care. "Competency is focuses on an individual's actual performance in a particular situation" (McConnell, 2001). A high level of interpersonal engagement and communication is needed when caring for cancer patients (Stajduhar et. al., 2010). Thus, effective communication is increasingly being recognized as a core clinical nursing skill and importance for building rapport with patients (Legg, 2011). The study aims to assess cancer patients satisfaction regarding nurses communication skills and to identify the relationship between some socio-demographic characteristics of cancer patients and nurses communication skills.

\section{MATERIALS AND METHOD}

The present study was carried out through the application of quantitative design (descriptive study) for cancer patients from $1^{\text {st }}$ of December, 2015, up to the $20^{\text {th }}$ of April, 2016 to assess Cancer Patient's Satisfaction Regarding Nurses Communication Skills in Azadi Teaching Hospital, which were receiving cancer patients. A non-probability (purposive) sample of (120) definitely diagnosed with cancer disease, selected from patients who were attended to these hospitals for receiving chemotherapy. Through extensive review of relevant literature, a questionnaire was constructed for the purpose of the study with interview technique. Overall items included in the questionnaire were (22) items. A panel of (11) experts was involved in the determination of the questionnaire content validity. The questionnaire consists of three parts, demographic data which is composed of (8) items which is (age, gender, residence, marital status, occupation, level of education, type of cancer, period of stay in hospital), patients's satisfaction regarding nature of NursePatient Communication \& patients's satisfaction regarding Therapeutic communication. These items were measured, scored and rated of 3-level Likert rating scale; frequently (3), sometimes (2), rarely (1). The data were collected through the utilization of constructed questionnaire, interview technique with cancer patients in oncology wards in Azadi teaching hospitals. The data collection process was performed from the period of $15^{\text {th }}$ of January, 2016 up to the $1^{\text {st }}$ March, 2016. Consent informed was granted from patients for participation in the present study was obtained and the interview was carried out individually. The data were analyzed through the application of descriptive statistical analysis which include (frequency and percentage, mean of score) and inferential statistical analysis which include (ANOVA and T-test).

\section{RESULTS}

Table (1): Distribution of the samples regarding demographic data with frequency and percentage

\begin{tabular}{||l|l|c|c||}
\hline \hline No. & \multicolumn{1}{|c|}{ Age(years) } & Frequency & Percentage \\
\hline 1 & $20-29$ & 20 & 16.7 \\
\hline 2 & $30-39$ & 19 & 15.7 \\
\hline 3 & $40-49$ & 23 & 19.2 \\
\hline 4 & $50-59$ & $\mathbf{2 9}$ & $\mathbf{2 4 . 2}$ \\
\hline 5 & $\geq 60$ & $\mathbf{2 9}$ & $\mathbf{2 4 . 2}$ \\
\hline Total & & 120 & 100 \\
\hline & Gender & Frequency & Percentage \\
\hline 1 & Male & $\mathbf{6 2}$ & $\mathbf{5 1 . 7}$ \\
\hline 2 & Female & 58 & 48.3 \\
\hline Total & & 120 & 100 \\
\hline No. & Level of Education & Frequency & Percentage \\
\hline 1 & Illiterate (Not read and Write) & $\mathbf{3 9}$ & $\mathbf{3 2 . 5}$ \\
\hline 2 & Read and Write & 20 & 16.6 \\
\hline 3 & Primary School Graduate & 27 & 22.5 \\
\hline 4 & Secondary School Graduate & 23 & 19.2 \\
\hline 5 & High Institute Graduate & 3 & 2.5 \\
\hline 6 & College and post Graduate & 8 & 6.7 \\
\hline Total & & 120 & 100 \\
\hline
\end{tabular}




\begin{tabular}{|l|l|c|c||}
\hline No. & Occupation & Frequency & Percentage \\
\hline 1 & Governmental Employed & 9 & 7.5 \\
\hline 2 & Free work & 28 & 23.4 \\
\hline 3 & Retired & 16 & 13.3 \\
\hline 4 & House wife & $\mathbf{4 8}$ & $\mathbf{4 0 . 0}$ \\
\hline 5 & student & 3 & 2.5 \\
\hline 6 & Jobless (unemployed) & 16 & 13.3 \\
\hline Total & & 120 & 100 \\
\hline No. & Marital Status & Frequency & Percentage \\
\hline 1 & Single & 15 & 12.5 \\
\hline 2 & Married & $\mathbf{1 0 5}$ & $\mathbf{8 7 . 5}$ \\
\hline Total & & 120 & 100 \\
\hline No. & residency & Frequency & Percentage \\
\hline 1 & Urban & $\mathbf{9 5}$ & $\mathbf{7 9 . 2}$ \\
\hline 2 & Rural & 25 & 20.8 \\
\hline Total & & 120 & 100 \\
\hline No. & Type of cancer & Frequency & Percentage \\
\hline 1 & Breast Ca. & $\mathbf{2 8}$ & $\mathbf{2 3 . 3}$ \\
\hline 2 & Hematologic Ca. & 23 & 19.2 \\
\hline 3 & Colon Ca. & 17 & 14.2 \\
\hline 4 & Lung Ca. & 16 & 13.3 \\
\hline 5 & Bone marrow Ca. & 10 & 8.3 \\
\hline 6 & Stomach Ca. & 8 & 6.7 \\
\hline 7 & Prostate Ca. & 6 & 5.0 \\
\hline 8 & other & 12 & 10.0 \\
\hline Total & & 120 & 100 \\
\hline No. & Period of staying in hospital & $\mathbf{8 5}$ & $\mathbf{7 0 . 8}$ \\
\hline 1 & 1 day $\geq$ & 10.8 \\
\hline 2 & 2-3 days & & 100 \\
\hline 3 & 4 days $\leq$ & Frequency & \\
\hline Total & & 25 & Percentage \\
\hline
\end{tabular}

Table (2): Distribution of cancer patients' satisfaction domains with frequency and percentage.

\begin{tabular}{|l|l|c|c|c|c|c|c|c|c||}
\hline \multirow{2}{*}{ No. } & $\begin{array}{l}\text { patients's satisfaction regarding } \\
\text { nature of Nurse-Patient } \\
\text { Communication }\end{array}$ & \multicolumn{2}{|c|}{ Always } & \multicolumn{2}{|c|}{ Sometimes } & \multicolumn{2}{|c|}{$\begin{array}{c}\text { Nean } \\
\text { of } \\
\text { Score }\end{array}$} & S. \\
\hline 1 & Nurse comes into patient's bed (room) & 92 & 76.6 & 23 & 19.2 & 5 & 4.2 & 2.72 & H.S \\
\hline 2 & $\begin{array}{l}\text { Nurse talks to patient's about treatment } \\
\text { process }\end{array}$ & 18 & 15.0 & 37 & 30.8 & 65 & 54.2 & 1.60 & L.S \\
\hline 3 & $\begin{array}{l}\text { Nurse seem to be interested when talk } \\
\text { with patients and when treating the } \\
\text { patients }\end{array}$ & 33 & 27.5 & 52 & 43.3 & 35 & 29.2 & 1.96 & M.S \\
\hline 4 & $\begin{array}{l}\text { When nurse talks with patients , he/she } \\
\text { sit beside the bed }\end{array}$ & 13 & 10.8 & 21 & 17.5 & 86 & 71.7 & 1.39 & L.S \\
\hline 5 & $\begin{array}{l}\text { Nurse involve the patients in an } \\
\text { important (next) steps of treatment }\end{array}$ & 53 & 44.2 & 54 & 45.0 & 13 & 10.8 & 2.33 & M.S \\
\hline 6 & $\begin{array}{l}\text { Nurse maintain eye contact with the } \\
\text { patients }\end{array}$ & 14 & 11.2 & 20 & 16.1 & 86 & 71.7 & 1.40 & L.S \\
\hline 7 & Nurse treats the patients with respect & 85 & 70.8 & 25 & 20.8 & 10 & 8.4 & 2.62 & H.S \\
\hline 8 & $\begin{array}{l}\text { Nurses Spent the right amount of time } \\
\text { with the patients }\end{array}$ & 17 & 14.2 & 31 & 25.8 & 72 & 60.0 & 1.54 & L.S \\
\hline 9 & $\begin{array}{l}\text { Nurses Talked in terms that the patients } \\
\text { could understand it }\end{array}$ & 9 & 7.5 & 37 & 30.8 & 74 & 61.7 & 1.45 & L.S \\
\hline
\end{tabular}




\begin{tabular}{|c|c|c|c|c|c|c|c|c|c|}
\hline \multirow[b]{2}{*}{ No. } & \multirow{2}{*}{$\begin{array}{l}\text { patients's satisfaction regarding } \\
\text { Therapeutic communication }\end{array}$} & \multicolumn{2}{|c|}{ Always } & \multicolumn{2}{|c|}{ Some times } & \multicolumn{2}{|c|}{ Never } & \multirow{2}{*}{$\begin{array}{c}\text { Mean } \\
\text { of } \\
\text { Score } \\
\end{array}$} & \multirow[b]{2}{*}{ S. } \\
\hline & & $\mathrm{F}$ & $\%$ & $\mathrm{~F}$ & $\%$ & $\mathrm{~F}$ & $\%$ & & \\
\hline 10 & $\begin{array}{l}\text { Introducing herself/himself to the } \\
\text { patients by name }\end{array}$ & 24 & 20.0 & 18 & 15.0 & 78 & 65.0 & 1.55 & L.S \\
\hline 11 & Addressing the patient by the name & 71 & 59.2 & 29 & 24.2 & 20 & 16.6 & 2.42 & H.S \\
\hline 12 & $\begin{array}{l}\text { Giving the patient time and ability to } \\
\text { explain himself/ herself, and listening to } \\
\text { the patients }\end{array}$ & 22 & 18.4 & 43 & 35.8 & 55 & 45.8 & 1.72 & M.S \\
\hline 13 & $\begin{array}{l}\text { Helping the patients to find the best } \\
\text { possible care solution }\end{array}$ & 23 & 19.2 & 64 & 53.3 & 33 & 27.5 & 1.91 & M.S \\
\hline 14 & $\begin{array}{l}\text { Setting and maintaining the appropriate } \\
\text { boundaries }\end{array}$ & 12 & 10 & 42 & 35 & 66 & 55 & 1.55 & L.S \\
\hline 15 & Smile with patient during talking & 60 & 50 & 39 & 32.5 & 21 & 17.5 & 2.32 & M.S \\
\hline 16 & $\begin{array}{l}\text { Nurses touch the patients when talking } \\
\text { with the patients }\end{array}$ & 18 & 15.0 & 31 & 25.8 & 71 & 59.2 & 1.55 & L.S \\
\hline 17 & Nurses uses clear and simple language & 68 & 56.7 & 30 & 25 & 22 & 18.3 & 2.38 & M.S \\
\hline 18 & $\begin{array}{l}\text { Nurses encourage the patients to ask } \\
\text { questions }\end{array}$ & 31 & 25.8 & 46 & 38.4 & 43 & 35.8 & 1.9 & M.S \\
\hline 19 & $\begin{array}{l}\text { Maintaining qualities of warmth and } \\
\text { friendliness throughout the helping } \\
\text { relationship }\end{array}$ & 75 & 62.5 & 33 & 27.5 & 12 & 10.0 & 2.52 & H.S \\
\hline 20 & $\begin{array}{l}\text { Convey continuous acceptance of the } \\
\text { patient and interest in discussing the } \\
\text { patients feelings with concern }\end{array}$ & 83 & 69.2 & 29 & 24.2 & 8 & 6.6 & 2.62 & H.S \\
\hline 21 & $\begin{array}{l}\text { patients trust in nurses what they are say } \\
\text { to them }\end{array}$ & 68 & 56.7 & 41 & 34.2 & 11 & 9.1 & 2.47 & H.S \\
\hline 22 & $\begin{array}{l}\text { Nurse providing a comfortable } \\
\text { environment }\end{array}$ & 15 & 12.5 & 40 & 33.3 & 65 & 54.2 & 1.58 & L.S \\
\hline
\end{tabular}

MS = moderately significant, $\mathrm{HS}=$ highly significant, $\mathrm{LS}=$ low significant, $\mathrm{F} .=$ frequency, $\%=$ percentage

Table (3): One-way analysis of variance for the differences between patient's satisfaction of communication skills domains and their age.

\begin{tabular}{|c|c|c|c|c|c|c|}
\hline category & S.O.V & Sum of square & df & $\begin{array}{l}\text { Mean } \\
\text { square }\end{array}$ & F. Obs. & Sig. \\
\hline \multirow{3}{*}{$\begin{array}{l}\text { Nature Of Nurse- } \\
\text { Patient Relationship }\end{array}$} & Between Groups & 58.172 & \multirow{3}{*}{$\begin{array}{c}4 \\
115 \\
119\end{array}$} & 14.543 & \multirow{3}{*}{1.883} & \multirow{3}{*}{.118} \\
\hline & Within Groups & 888.328 & & \multirow{2}{*}{7.725} & & \\
\hline & Total & 946.500 & & & & \\
\hline \multirow{3}{*}{$\begin{array}{l}\text { Therapeutic } \\
\text { Communication }\end{array}$} & Between Groups & 313.851 & \multirow{3}{*}{$\begin{array}{c}4 \\
115 \\
119\end{array}$} & 78.463 & \multirow{3}{*}{2.869} & \multirow{3}{*}{.026} \\
\hline & Within Groups & 3144.941 & & \multirow{2}{*}{27.347} & & \\
\hline & Total & 3458.792 & & & & \\
\hline
\end{tabular}

F critical $=2.45$

Table (4): comparison of cancer patient's satisfaction domains regarding to their gender

\begin{tabular}{||l|l|c|c|c|c|c||}
\hline \multicolumn{1}{|c|}{ category } & \multicolumn{1}{|c|}{ sex } & No. & $\mathbf{X}$ & SD & T. obs. & Sig \\
\hline $\begin{array}{l}\text { Nature Of Nurse- } \\
\text { Patient Relationship }\end{array}$ & Male & 62 & 17.01 & 2.107 & \multirow{2}{*}{4.079} & \multirow{2}{*}{ S. } \\
\cline { 2 - 7 } $\begin{array}{l}\text { Therapeutic } \\
\text { Communication }\end{array}$ & Female & 58 & 17.12 & 2.506 & & \multirow{2}{*}{ NS. } \\
\cline { 2 - 6 } & Male & 62 & 26.59 & 2.888 & 2.786 & \\
\hline
\end{tabular}

T critical $=1.980$

Df $=118$ 
Table (5): comparison between patient's satisfaction domains regarding their marital status

\begin{tabular}{|c|c|c|c|c|c|c|}
\hline Category & Marital Status & No. & $\mathbf{X}$ & $\overline{\text { Sd }}$ & T. Obs. & $\overline{\text { Sig }}$ \\
\hline \multirow{2}{*}{$\begin{array}{l}\text { nature of nurse-patient } \\
\text { relationship }\end{array}$} & single & 15 & 16.46 & 2.642 & \multirow{2}{*}{0.180} & \multirow{2}{*}{ NS. } \\
\hline & married & 105 & 15.64 & 2.841 & & \\
\hline \multirow{2}{*}{$\begin{array}{l}\text { therapeutic } \\
\text { communication }\end{array}$} & single & 15 & 21.66 & 6.789 & \multirow{2}{*}{4.702} & \multirow{2}{*}{ S. } \\
\hline & married & 105 & 24.00 & 5.134 & & \\
\hline
\end{tabular}

$\mathrm{T}$ critical $=1.980$, Df $=118$

Table (6): One-way analysis of variance for the difference between patient's satisfaction of communication skills domains and their period of staying in hospitals.

\begin{tabular}{|c|c|c|c|c|c|c|}
\hline category & S.O.V & Sum of square & df & $\begin{array}{c}\text { Mean } \\
\text { square }\end{array}$ & F. Obs. & Sig. \\
\hline \multirow{3}{*}{$\begin{array}{l}\text { Nature Of Nurse- } \\
\text { Patient Relationship }\end{array}$} & Between Groups & .143 & \multirow{3}{*}{$\begin{array}{c}2 \\
117\end{array}$} & .072 & \multirow{3}{*}{.013} & \multirow{3}{*}{.987} \\
\hline & Within Groups & 629.324 & & \multirow{2}{*}{5.379} & & \\
\hline & Total & 629.467 & & & & \\
\hline \multirow{3}{*}{$\begin{array}{l}\text { Therapeutic } \\
\text { Communication }\end{array}$} & Between Groups & 3.340 & \multirow[b]{3}{*}{117} & 1.670 & \multirow{3}{*}{.206} & \multirow{3}{*}{.814} \\
\hline & Within Groups & 948.452 & & 8106 & & \\
\hline & Total & 951.792 & & 8.106 & & \\
\hline
\end{tabular}

F critical $=3.07$

\section{DISCUSSION}

Table (1) shows that the highest percentage $(r \varepsilon, r \%)$ of study sample were at age group (50-59 and $\geq 60$ )years old, $(51.7 \%)$ of the study sample were male, $(32.5 \%)$ of study sample were illiterate, $(40.0 \%)$ of the study sample were housewife, $(87.5 \%)$ of the study sample were married, (79.2\%) of the study sample were urban residency, $(23.3 \%)$ of study sample have breast cancer, and (70.8\%) of study sample were staying $\geq 1$ day in hospital. Table $(r)$ shows that the highly significant of patients' satisfaction regarding the nature of nurse-patient communication found in items $(1,7)$, low significant found in items $(2,4,6,8$, and 9). Also this table shows that the highly significant of patients's satisfaction regarding Therapeutic communication found in items $(11,19,20$, and 21), low significant found in items $(10,14$, 16, and 22). Table (3) shows that there is no significant relationship between the nature of nurse-patient's relationship domain, and their is significant relationship between therapeutic communication domain with the patients age at $\mathrm{P} \leq 0.05$. Table (4) shows that there is significant differences between the Nature Of Nurse-Patient Relationship, and there is not significant differences between Therapeutic Communication according to their gender at $\mathrm{P}$ value $\leq 0.05$. Table (5) shows that there no significant differences between the Nature of Nurse-Patient Relationship domain, and there is significant differences between Therapeutic Communication domain according to their marital status at $\mathrm{P}$ value $\leq 0.05$. Table (6) shows that there is no significant relationship between patient's satisfaction of communication skills domains and their period of staying in hospitals at $\mathrm{P}<0.05$. As professionals, oncology nurses play an important role in cancer diagnosis and management and they contribute toward their patients' quality of life and survival. For nurses to be effective in fulfilling their roles, they must have a well-defined set of professional competences to ensure that they are able to deliver the highest quality nursing care. "Competency is focuses on an individual's actual performance in a particular situation" (McConnell, 2001). The results of the study showed that the satisfaction of the patients regarding communication divided in to two domains; satisfaction regarding the nature of nurse-patient communication and satisfaction regarding therapeutic communication. According to the nature of the communication the results showed that the patients were dissatisfied on nurses' communication. Shortage of nursing staff, hurry up during administration of chemotherapy, uninterested with the patient's condition, also too many cases in the oncology unit all these can lead to lack of communication with the patients. Oncology nurse may lack the communication programs to be effective communicator. Since nurses, in comparison with other medical staff, spend more time with patients, educating them in communication skills is so important and can help improve the quality of medication (Charlton et. al., 2008). This 
results disagreement with the study conducted by Ayman et. al. (2013) that their study reveal satisfaction about nursing competency in practicing communication skills. McAllister (2003) states that unlike the modern medication in which the patients' problems are focused on instead of the patient him or herself, the focus of nursing care is based on humanistic relations and individual's communication skills. The nursing staff can easily manage the stress caused by communication with patients and have a better tendency for building rapport with patients if they get familiar with solution-focused approach to communication. The nurses communicate with cancer patient to build trust towards established for close relationship. They communicate with the family to give moral support. When cancer patient can communicate well with the nurses, they accept the nurses' recommendation better. Nurses communicate with patients verbally and non-verbally. Nonverbal communication can make the cancer patient feel appreciated during cancer treatment process. Usually, the nurses and cancer patients are communicate about the process of cancer treatment and all the side effect. The nurses also communicate about the treatment and side effects with the patients' family. (Aida et. al., 2013) According to the therapeutic communication, the nurses should use appropriate interpersonal skills to deliver nursing care to the patients especially cancer patients. The results showed that the patients were dissatisfied in some items; introducing the patients by name, Setting and maintaining the appropriate boundaries, using touch when talking with the patients, and Nurse providing a comfortable environment. A large number of cases diagnosed with cancer, cultural differences in Kirkuk region may interfere with the nursing job and may be considered barriers to communicate with the patients. According to the study conducted by Ayman et. al. (2014) there were no significant differences in patients' satisfaction about nurses' communication skills in regards to demographic characteristics except for medical diagnoses in which patients diagnosed with cancer had different perception. The results agree with previous reports that patients' perception of nurses' communication skills is affection by patients' demographics. Previous studies found that patients diagnosed with cancer had different perception of nurses' communication skills (Ayman et. al., 2014). One possible explanation is that patients in specialized care units such as oncology and palliative care units may have longer period of interaction and their disease process also may have an influence on their satisfaction level about nurses' communication skills. On the other hand, patients in general wards have less contact time with their nurses that influence their level of satisfaction about their nurses' communication skills (Ayman et. al., 2014). The results revealed that there is a significant difference between cancer patient satisfaction and gender, this results agree with the study conducted by Shermeh et. al. (2013) that there was a statistically significant correlation between gender and participants' scores in communication skills in the pretest. The mean score for female nurses was higher than that of male participants. However, after doing the covariance analysis for the posttest, gender had no significant effect ( $p=0$.07). These findings are in line with those of Karimzadeh et al. 2009 and Baerheim et al 2007 (Karimzade et. al., 2009; Baerheim et. al., 2007).

\section{CONCLUSION}

The results showed that the patients were dissatisfied on the nature of nurse-patient relationship especially in items (When nurse talks with patients, he/she sits beside the bed and Nurse maintains eye contact with the patient). The results showed that the patients were dissatisfied on the therapeutic communication especially in item (Introducing herself/himself to the patients by name), and satisfied in item (Convey continuous acceptance of the patient and interest in discussing the patients feelings with concern). The results show that there is significant relationship between cancer patients age, gender, and marital status with the therapeutic communication. There is no significant relationship between periods of staying in hospital with the nature of relationship.

\section{RECOMMENDATIONS}

The present study recommends that trained educational program should be designed to increase nurses' awareness and knowledge about modes of communication. Nursing staff should be increased suitable with the number of cancer patients available in the oncology unit. Providing posters, booklet, publication and journal about communication skills. Health organizations should provide nursing staff with comfortable and privet environment. Further research should be conducted in Kirkuk hospital for all patients. 


\section{REFERENCES}

Aida, N.; Eric, S.; Muhamad, M.; and Hasnaa, N. (2013). Communication Competencies of Oncology Nurses in Malaysia. Asian Pacific Journal of Cancer Prevention. 14 (1). 153-158

Ayman, M.; Ahmad, E.; Aboshaiqah, B.; Imad, N.; Wisam, M.; Salim, R.; Saleh, N.; Azzeghaiby, Muna A.; Anani, R. (2014). Patients' satisfaction about nurses' competency in practicing communication skills. Life Science Journal. 11(3). P.p. 339- 34.

Baerheim, A.; Hjortdahl, P.; Holen, A.; Anvik, T.; Fasmer, O.; Grimstad, H. (2007). Curriculum Factors Influencing Knowledge Of Communication Skills Among Medical Students. BMC Medical Education. 7(1). 35.

Billing, K.; Newland, H.; Selva, D. (2007). Improving patient satisfaction through information provision. Clin Experiment Ophthalmol. 35(5). 439-47.

Charlton, C.; Dearing, K.; Berry, J.; Johnson, M. (2008). Nurse Practitioners Communication Styles and Their Impact On Patient Outcomes: An Integrated Literature Review. Journal of the American Academy of Nurse Practitioners. 20(7). P.p.382-388.

Hickson, GB.; Clayton, EW.; Entman, SS.; Miller, CS.; Githens, PB.; WhettenGoldstein, K.; et. al.(1994). Obstetricians' prior malpractice experience and patients' satisfaction with care. JAMA. 272(20). P.p.1583-7.

Karimzade, M.; Tafti, M.; Akbarzade, N. (2009). Effect of Teaching The Social-Emotional Skills On Developing These Skills. Journal of Behavioral Sciences. 3(2). P.p.143-149.

Keating, NL.; Green, DC.; Kao, AC.; Gazmararian, JA.; Wu, VY.; Cleary, PD. (2002). How are patients' specific ambulatory care experiences related to trust, satisfaction, and considering changing physicians?. J Gen Intern Med. 17(1). P.p. 29-39.

Kurpas, D.; Steciwko, A. (2005). Patient satisfaction as the main indicator of primary care quality. Przegl Lek. 62(12). P.p.1546-51.

Legg, MJ. (2011). What is psychosocial care and how can nurses better provide it to adult oncology patients. Aust J Adv Nursing. 28. P.p.61-67.

Mcallister, M. (2003). Doing Practice Differently: Solution-Focused Nursing. Journal of Advanced Nursing. 41(6). P.p.528-535.

McCabe, C.; and Timmins, F. (2006). Communication Skills for Nursing Practice. Palgrave MacMillan.

McConnell, EA. (2001). Competence vs competency. Nursing Manage. 32. P.p.1415 .

Pitrou, I.; Lecourt, AC.; Bailly, L.; Brousse, B.; Dauchet, L.; Ladner, J. (2009). Waiting time and assessment of patient satisfaction in a large reference emergency department: a prospective cohort study, France. Eur J Emerg Med. 16(4). P.p.17782.

Shermeh, S.; Amiri, H.; Zarchi, A.; Bahari, F.; Binesh, A. (2013). Effectiveness of Solution-Focused Communication Training (SFCT) in Nurses' Communication Skills. Iranian Journal of Military Medicine. 14 (4). P.p.279- 286

Stajduhar, KI.; Thorne, SE.; McGuinness, L.; Kim-Sing, C. (2010). Patient perceptions of helpful communication in the context of advanced cancer. J Clin Nursing. 19. P.p.2039-47.

Stelfox, HT.; Gandhi, TK.; Orav, EJ.; Gustafson, ML. (2005). The relation of patient satisfaction with complaints against physicians and malpractice lawsuits. Am J Med. 118(10). P.p.1126-33.

Westbrook, JI. (1993). Patient satisfaction: methodological issues and research findings. Aust Health Rev. 16(1). P.p.7588 . 